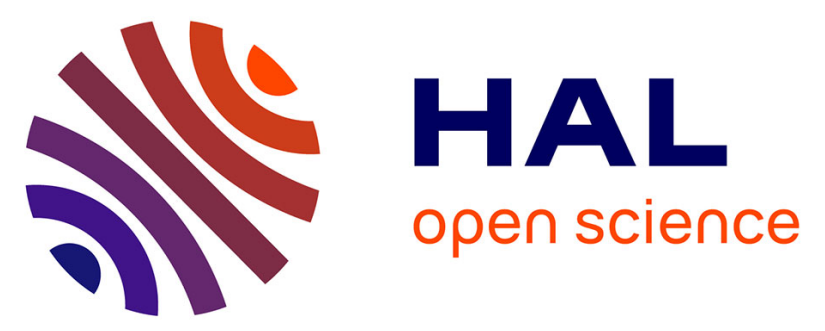

\title{
EXPERIMENTAL DETERMINATION OF THE SPATIO-TEMPORAL DISTRIBUTION OF THE SPACE CHARGE FIELD IN A BREAKDOWN
}

P. Bayle, Maxime Bayle, E. Morales

\section{- To cite this version:}

P. Bayle, Maxime Bayle, E. Morales. EXPERIMENTAL DETERMINATION OF THE SPATIOTEMPORAL DISTRIBUTION OF THE SPACE CHARGE FIELD IN A BREAKDOWN. Journal de Physique Colloques, 1979, 40 (C7), pp.C7-249-C7-250. 10.1051/jphyscol:19797122 . jpa-00219094

\section{HAL Id: jpa-00219094 https://hal.science/jpa-00219094}

Submitted on 1 Jan 1979

HAL is a multi-disciplinary open access archive for the deposit and dissemination of scientific research documents, whether they are published or not. The documents may come from teaching and research institutions in France or abroad, or from public or private research centers.
L'archive ouverte pluridisciplinaire HAL, est destinée au dépôt et à la diffusion de documents scientifiques de niveau recherche, publiés ou non, émanant des établissements d'enseignement et de recherche français ou étrangers, des laboratoires publics ou privés. 


\section{EXPERIMENTAL DETERMINATION OF THE SPATIO-TEMPORAL DISTRIBUTION} OF THE SPACE CHARGE FIELD IN A BREAKDOWN

P. Bayle, M. Bayle, E. Morales.

Centre de Physique Atomique, Laboratoire associé au C.N.R.S. $n^{\circ}$ 277, Université Paul Sabatier, Toulouse.

Ionizing processes occuring during a breakdown are generally analysed through optical devices, photomultipliers or image converters. Though less sensitive than photomultipliers, the streak image converters have the advantage of giving a continuous spatio temporal representation of the dis charge; this is particularly interesting in the case of non recurrent discharges. We have thus developped a technique to interpret streak camera records that give us the parameters governing the discharge, and in particular the space charge field. It is known that a breakdown is essentially governed by the field resulting from the superposition of the applied field and the space-charge field (1)(2).

It is possible to sort out two kinds of informations from the streak camera records :

a) information of geometric order that gives the dimension, the position of the discharge and its propagation speed (3). These are essentially qualitative informations.

b) information about the energies related to the blackening density of the film. For a film emulsion, the characteristic curve links the image density $D(x, t)$ to the Iuminous energy received. The blackening density $D(x, t)$ is related to the number $\phi$ of photons present at the corresponding point $(x, t)$ in the discharge. As a first approximation this relation can be expressed by $D(x, t)=T \operatorname{Lg}[T \phi(x, t)]$ where $\Gamma$ is the film contrast ratio and $T$ is the transmission function of the experimental set up.

The number of photons emitted between time $t$ and $t+d t$ at a distance $x$ from the cathode is given by $d \phi(x, t)=\frac{1}{\tau}\left[\int_{0}^{t} n_{e}\left(x, t^{\prime}\right) \delta\left(x, t^{\prime}\right) v_{e}\left(x, t^{\prime}\right) \exp \left[-\frac{t-t^{\prime}}{\tau}\right] d t^{\prime}\right] d t$ $\boldsymbol{r}$ is the mean decay time constant of excited states $\frac{\delta(x, t)}{p}=F \exp \left[-\frac{G p}{E(x, t)}\right]$

is the light excitation coefficient by electrons (4)

$$
v_{e}(x, t)=\mu \frac{E(x, t)}{p} \quad \text { the drift velocity }
$$

$n_{e}(x, t)$ is the electron density distribution $n_{c}(x, t)=n_{0} \exp \left[\int_{0}^{t} \alpha(x, \zeta) v_{e}(x, \xi) d \xi\right]$ $\alpha(x, t) / p=A \exp [-B p / E(x, t)]$

As the macroscopic coefficients are functions of the electric field, we obtain from relations (1) and (2), the electric field. If $y(x, y)=E(x, t) / p$, we obtain. $\frac{\partial y}{\partial t}=\left\{\frac{1}{\Gamma} \frac{\partial D}{\partial t}+\frac{\tau\left[\frac{\partial^{2} D}{\partial t^{2}}+\frac{2}{\Gamma} \frac{\partial^{2} D}{\partial t^{2}} \frac{\partial D}{\partial t}\right]+\frac{\partial^{2} D}{\partial t^{2}}}{\left[\frac{\partial^{2} D}{\partial t^{2}}+\frac{1}{\Gamma}\left(\frac{\partial D}{\partial t}\right)^{2}\right]+\frac{\partial D}{\partial t}}-A \mu y+p\left[-\frac{8}{y}\right]\right\}\left\{\frac{1}{y}+\frac{6}{\eta^{2}}\right]^{-1}$ Equation (3) shows the dependency of the electric (3) field on the first derivatives of the optical density of the streak camera record. This dependency indicates important perturbations of the field that will appear at the bounderies of the light and dark areas.

A diagram of the streak camera record is given in fig. 1 ; analysis of the record was carried out by means of scanning microdensitometer that gives the matrix $D(x, t)$. The isodensity curve are shown in fig. 1. One can see the propagation of a cloud of electrons between the cathode and the anode. The cloud widens out and is then followed by a second discharge canal of lower speed. The impact of the electrons cloud on the anode gives rise to a return front in the direction of the cathode, where it produces a second luminous front that goes back to-. wards the anode.

Equation (3) is solved with respect to time for each value of $x$. This give us the continuous evolution of the electric field with position and time. In fig. 2 we show the analysis corresponding to the line indicated by arrows on fig. 1 . The field is derived, 
which amounts to heglecting memory effects on the recorded picture due to the lifetime of the excited states. We have for example in fig. 2 the evolution $E\left(x_{i}, t\right)$ of the field in time at a given point in the gap. The optical density increases in an almost monotonous manner. The first luminous front corresponds to a maximum in optical density, while the two other fronts, the anode and cathode return waves give a modification of the gradient of the optical density as a function of time (5).

Each luminous front can be associated to the propagation of a strong perturbation of the electric fields as one can see on fig. 2. The propagation of a luminous front indicates the propagation of an ionizing wave. The perturbation of the field happens in the following way : in front of the wave there exists a strong field that corresponds to a zone of high optical density gradient, this wave leaves a zone of almost neutral plasma characterized by a weak electric field behind. The wave after reflection on the anode reinforces the electric field. The arrival of the ionizing wave at anode gives rise to an intense anodic spot. The spot is related to a very strong space charge field due to the electron cloud just in front of the anode. The gradual absorption of the electrons by the anode modifies the net charge near the electrode. Once the electrons are absorbed, the cloud of remaning positive ions lowers the field at the anode, while the field towards the cathode, become more strong fig. 3. This perturbation goes towards the cathode. The propagation speed of the luminous front and that of the ionizing wave are little different, because the propagation is, in fact governed by the ionizing wave. The stronger the ionization of the gas the faster is the propagation. The last wave can cross the gap $(5 \mathrm{~cm})$ in one nanosecond.

(1) Yoshida (K.), Tagashira (H.) : J. Phys. D. Appl. Phys. 9, 485-490 (1976).

(2) Davies (A.J.), Evans (C.J.), Townsend (P.), Woodison (P.M.) : Proc. IEE, Vol. 124, $\mathrm{n}^{\circ} 2$. 179-182 (1977).

(3) Bayle (P.), Bayle (M.), Crokaert (M.) : J. Phys. D. Appl. Phys, 8, 2181-2189, (1975).

(4) Legler (W.) : Zeit. Phys. 143, 173-190, (1955).

(5) Bayle (P.), Bayle (M.), Morales (E.) : J.

Phys, D. Appl. Phys. To be published.

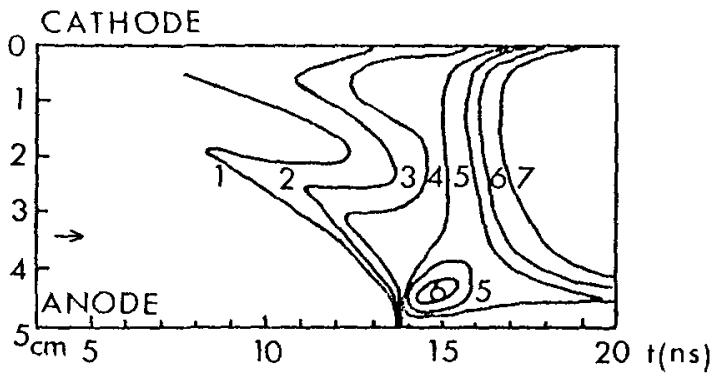

Fig. 1. Microdensitogram of streak photograph of discharge in $\mathrm{N}_{2}+\mathrm{CH}_{4}(2.5 \%)$, $\mathrm{P}=130$ torr, $\mathrm{E}_{\mathrm{o}} / \mathrm{P}=118 \mathrm{~V} / \mathrm{cm}$. torr.

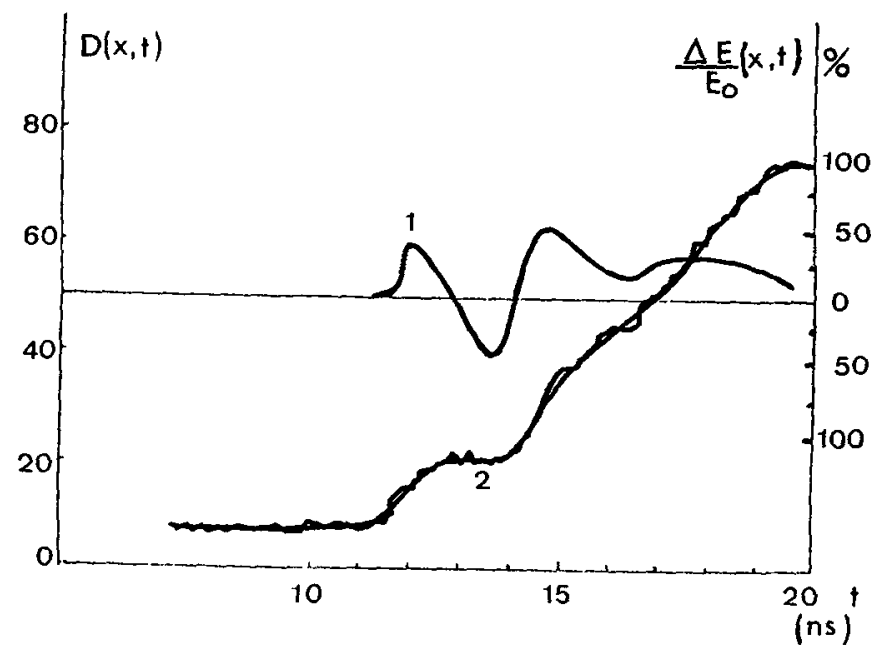

Fig. 2. Electric field (1) and optical density (2) at $x=33.5 \mathrm{~mm}$ from the cathode.

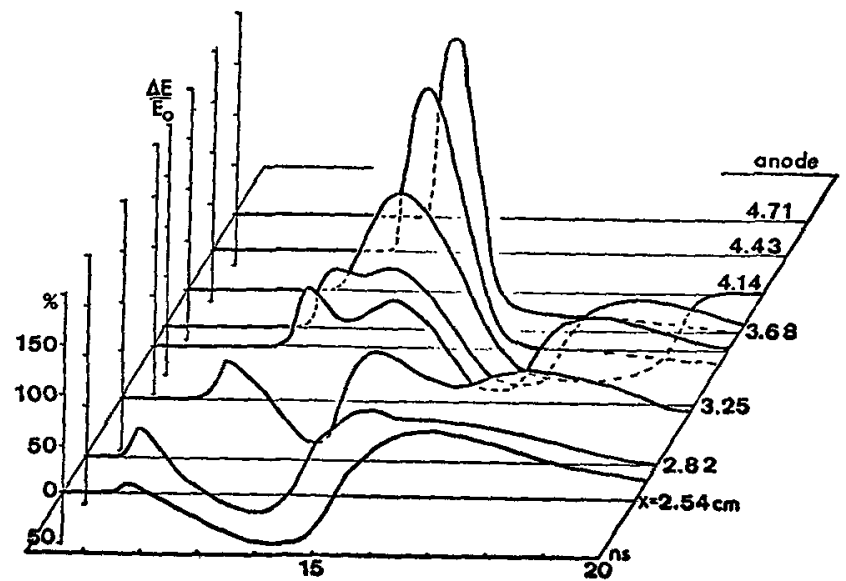

Fig. 3. Perturbation of electric field at the anode. ( $x=$ distance from the cathode). 